\title{
Mineral alteration in ammonia-water solutions
}

\author{
AMBER ZANDANEL ${ }^{1}$, ROLAND HELLMANN ${ }^{2}$ AND \\ LAURENT TRUCHE ${ }^{3}$ \\ ${ }^{1}$ Université Grenoble Alpes \\ ${ }^{2}$ ISTerre \\ ${ }^{3}$ ISTerre, Université Grenoble Alpes \\ Presenting Author: azandanel@gmail.com
}

Introduction: The identification of a liquid ocean beneath the ice crust on Saturn's small moon Enceladus has kindled interest in low-temperature water-rock interactions as a driver in developing habitable worlds [1], [2]. The preservation of $\mathrm{NH}_{3}$ and salts that depress the freezing point of water in small, cold satellites suggest that the heat generated from exothermic mineral dissolution at below- $0{ }^{\circ} \mathrm{C}$ could even initiate the ice melting processes that create liquid oceans [3]. However, numerical models of mineral dissolution in these environments often rely on thermodynamic and kinetic data extrapolated from $25{ }^{\circ} \mathrm{C}$ or above.

Methods: Batch experiments combined San Carlos olivine $\left(\mathrm{Mg}_{1.83} \mathrm{Fe}_{0.17} \mathrm{SiO}_{2}\right)$ with $\mathrm{NH}_{3}-\mathrm{H}_{2} \mathrm{O}$ solutions, reacted at $-20,4$, and $22{ }^{\circ} \mathrm{C}$ for up to 442 days. Solution chemistry changes were monitored at intervals to evaluate mineral alteration over time. The ice-fluid-mineral interface was characterized using Raman spectroscopy and geochemical modelling. In addition, olivine surfaces were analyzed at the nanoscale with TEM microscopy.

Results: Changes to fluid chemistry over time show that olivine dissolution occurs even in partially frozen solutions. Initial evolution of concentrations of $\mathrm{Si}$ and $\mathrm{Mg}$ show a surprisingly weak dependence on temperature, $\mathrm{pH}$, and $\mathrm{NH}_{3}$, while long-term rates show an apparent weak inverse relationship with temperature. Our findings imply that olivine dissolution is not significantly retarded at $-20^{\circ} \mathrm{C}$ compared to 22 ${ }^{\circ} \mathrm{C}$. In addition, high-resolution TEM analysis of the olivine surface after 442 days of reaction shows a thin $(<1 \mathrm{~nm})$ altered layer at the olivine surface, unambiguously demonstrating that secondary reaction products can form in partially frozen solutions even at experimental timescales. These findings are applicable to evaluating mineral weathering processes in frozen or partially-frozen icy worlds such as Enceladus, (1) Ceres, or Uranus' moon Ariel.

Acknowledgments: This study acknowledges the financial support from the French Agence Nationale de Recherche, project ANR OASIS (grant $\mathrm{N}^{\circ}$ ANR-16-CE31-0023-01.

\section{References:}

[1] Waite, J. H. et al. (2016) Science, 356, 155-159. [2] Deamer, D. and Damer, B. (2017) Astrobiology, 17, 834-839. [3] Malamud, U. and Prialnik, D. (2013) Icarus 225, 763-774. 